\title{
Autistic enterocolitis: Fact or fiction?
}

\author{
Polymnia Galiatsatos MD FRCPC ${ }^{1}$, Adrian Gologan $\mathrm{MD}^{2}$, Esther Lamoureux MD FRCPC ${ }^{2}$
}

P Galiatsatos, A Gologan, E Lamoureux. Autistic enterocolitis: Fact or fiction? Can J Gastroenterol 2009;23(2):95-98.

Autism spectrum disorder refers to syndromes of varying severity, typified by impaired social interactions, communicative delays and restricted, repetitive behaviours and interests. The prevalence of autism spectrum disorders has been on the rise, while the etiology remains unclear and most likely multifactorial. There have been several reports of a link between autism and chronic gastrointestinal symptoms. Endoscopy trials have demonstrated a higher prevalence of nonspecific colitis, lymphoid hyperplasia and focally enhanced gastritis compared with controls. Postulated mechanisms include aberrant immune responses to some dietary proteins, abnormal intestinal permeability and unfavourable gut microflora. Two autism spectrum disorder patients with chronic intestinal symptoms and abnormal endoscopic findings are described, followed by a review of this controversial topic.

Key Words: Autism; Asperger's; Enterocolitis; Gastritis

\section{Entérocolite autistique : Réalité ou fiction?}

\begin{abstract}
Les troubles du spectre autistique font référence à des syndromes de gravité diverse, caractérisés par une perturbation des interactions sociales, des retards sur le plan de la communication, ainsi que des comportements et des intérêts limités et répétés. La prévalence des troubles du spectre autistique est en hausse, tandis que leur étiologie reste imprécise et fort probablement multifactorielle. Plusieurs rapports ont avancé l'hypothèse d'un lien entre l'autisme et certains symptômes gastro-intestinaux chroniques. Des études endoscopiques ont notamment montré une prévalence plus élevée de colite non spécifique, d'hyperplasie lymphoïde et de gastrite en foyers chez des sujets malades comparativement à des témoins. Parmi les mécanismes potentiellement en cause, on retrouve : réponse immunitaire aberrante à certaines protéines alimentaires, perméabilité intestinale anormale et microflore intestinale inappropriée. On décrit ici le cas de deux patients atteints de troubles du spectre autistique qui présentaient des symptômes intestinaux chroniques et des anomalies endoscopiques, le tout est suivi d'une revue sur ce sujet controversé.
\end{abstract}

\section{CASE PRESENTATIONS}

Case 1

An 18-year-old man, working on a farm, presented with a fiveyear history of bloating and abdominal cramps. He denied having any diarrhea, constipation or rectal bleeding. His medical history was remarkable for a diagnosis of autism spectrum disorder in early childhood, for which he received very little intervention due to the paucity of services in his rural community. There was no family history of gastrointestinal diseases.

On examination, the patient was noted to be tall and thin, with a body mass index of $20 \mathrm{~kg} / \mathrm{m}^{2}$. There were no oral mucosal lesions, cervical adenopathy or palpable abdominal masses or tenderness. At the onset of his symptoms, the patient had undergone a gastroscopy and colonoscopy which were normal.

A gastroscopy repeated one year previously, however, showed a 'mild nonspecific gastritis', in the absence of Helicobacter pylori infection or nonsteroidal anti-inflammatory use. The patient's symptoms actually worsened on a trial of proton pump inhibitor; consequently, the medication was discontinued. A subsequent small-bowel follow-through was unremarkable. The patient was then given a trial of an antispasmodic drug pinaverium bromide (Dicetel, Solvay Pharma Inc, Canada) which also did not improve his symptoms. Finally, a colonoscopy was repeated, revealing small, round centrally clearing lesions in the rectum and ascending colon consistent with focal active colitis (Figure 1), as well as lymphoid hyperplasia of the terminal ileum. Because there were no true signs of chronic gland damage or granulomata, a diagnosis of Crohn's disease could not be

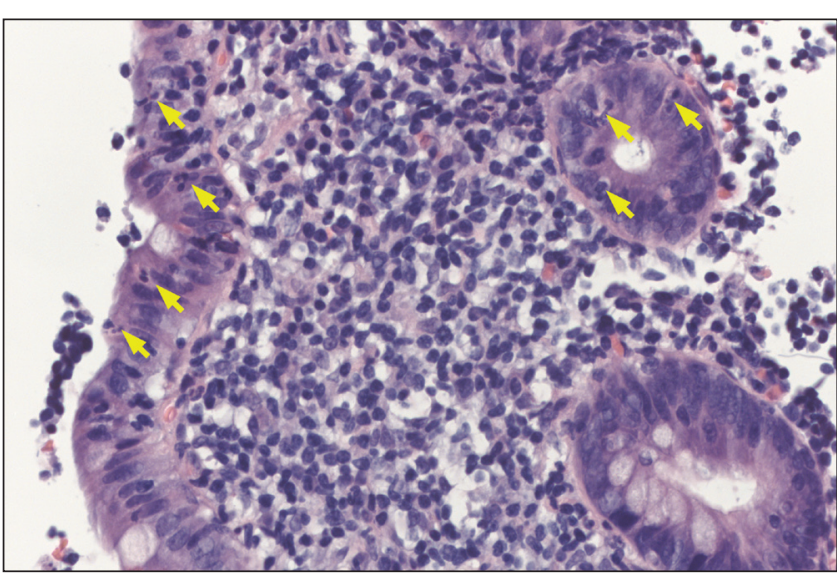

Figure 1) Aphthoid lesion in the colon showing a mucosal lymphoid follicle associated with neutrophilic infiltration surface epithelium and crypts (arrows) (hematoxylin and eosin stain, original magnification $\times 200$ )

made. The patient failed a trial of high-dose 5-aminosalicylic acid therapy, but improved on a tapering course of steroids.

Case 2

A 19-year-old woman presented with a long-standing history of upper abdominal discomfort, bloating and constipation. While her symptoms were not consistently preceded by specific food ingestion, the patient reported feeling remarkably improved

${ }^{1}$ Division of Gastroenterology, Department of Medicine; ${ }^{2}$ Department of Pathology, The Sir Mortimer B Davis Jewish General Hospital,

McGill University, Montreal, Quebec

Correspondence: Dr Polymnia Galiatsatos, Division of Gastroenterology, Room G-327, Sir Mortimer B Davis Jewish General Hospital,

3755 Cote-Ste Catherine, Montreal, Quebec H3T 1E2. Telephone 514-340-8144, fax 514-340-8282,

e-mail pgaliatsatos@jgh.mcgill.ca

Received for publication April 23, 2008. Accepted May 19, 2008 


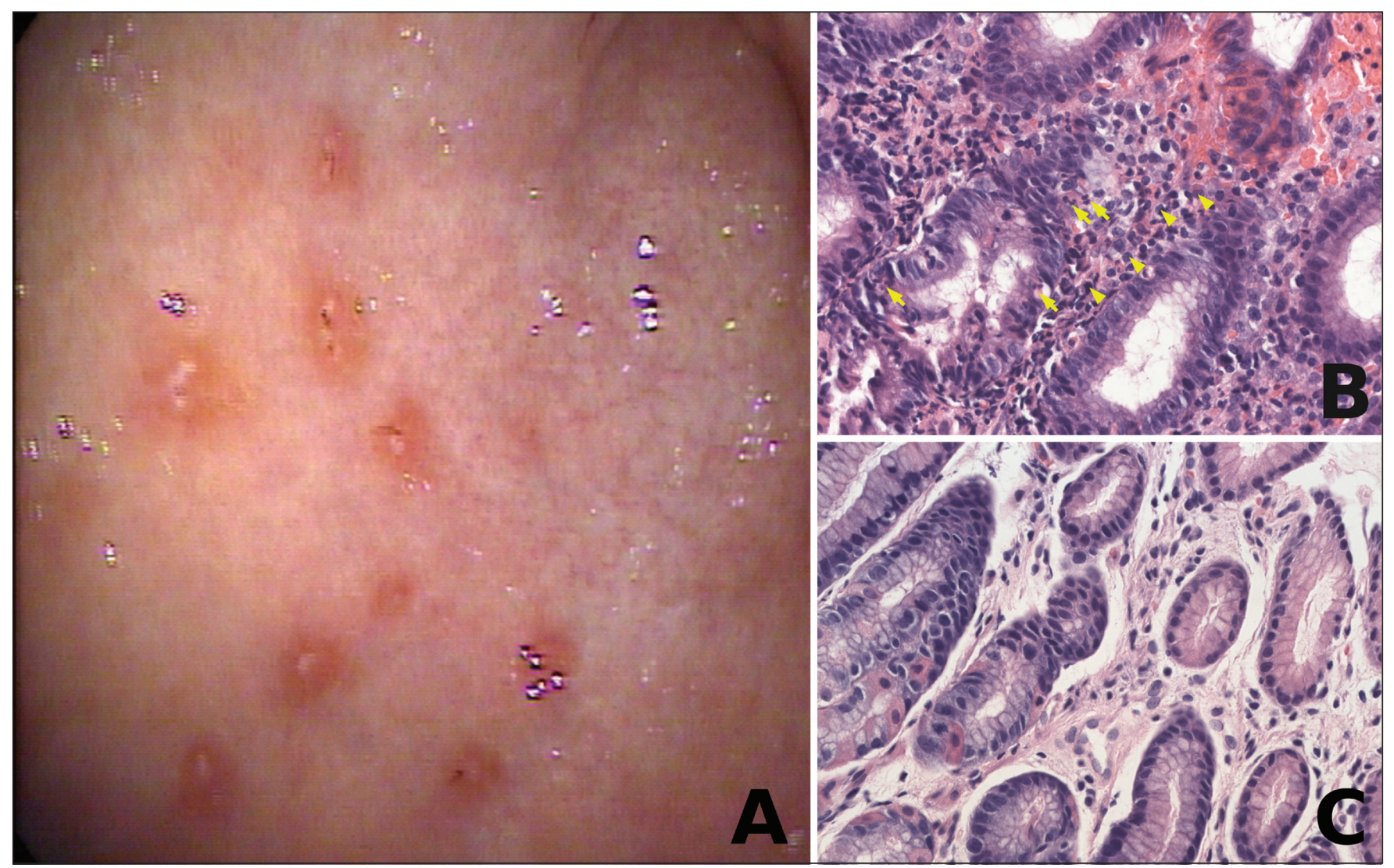

Figure 2) A Endoscopic image of gastric antrum, showing punctate erosions with reddish halo; B Focus of chronic active gastritis in the antral mucosa with polymorphonuclear neutrophils infiltrating the foveolar epithelium (arrows) and lymphoplasmacytic infiltrate in lamina propria (arrow heads) (hematoxylin and eosin stain, original magnification $\times 200$ ); C Gastric antral mucosa obtained during the same procedure and showing only minimal lamina propria lymphocytic infiltrate and no active inflammation (hematoxylin and eosin stain, original magnification $\times 200$ )

in the few months before consultation on a self-imposed glutenfree diet. The patient denied any weight loss or rectal bleeding, and was not on any prescription or over-the-counter medications. Her medical history was remarkable for chronic iron deficiency anemia, which had been attributed to menorrhagia, as well as a very recent diagnosis of Asperger's syndrome (AS), based on persistent maladaptive social behaviour. Of note, the patient's three-year-old sister had also been diagnosed with AS, and her mother was being treated for irritable bowel syndrome. There was no family history of celiac disease or inflammatory bowel disease.

On examination, the patient was noted to be of short stature and her vital signs were normal. There were no apparent skin lesions or oral ulcers. Her cardiopulmonary and abdominal examinations were unremarkable. There was no palpable hepatosplenomegaly or inguinal adenopathy.

A complete blood count was normal (hemoglobin $133 \mathrm{~g} / \mathrm{L}$ ), with a ferritin level of $18 \mu \mathrm{g} / \mathrm{L}$ off iron supplements. A lactose breath test was strongly positive for malabsorption. She subsequently underwent a gastroscopy following a two-month gluten challenge. At the time of gastroscopy, she was noted to have multiple punctate erosions, surrounded by a reddish halo, predominantly in the antrum, and to a lesser extent, in the gastric body (Figure 2A). The first and second stage of the duodenum appeared macroscopically unremarkable. Biopsies taken from the stomach revealed a focally accentuated chronic active gastritis, in the absence of granulomata (Figures $2 \mathrm{~B}$ and $2 \mathrm{C}$ ).
Giemsa stain and immunostaining were negative for $\mathrm{H}$ pylori organisms. Duodenal biopsies were normal.

\section{DISCUSSION}

Autism spectrum disorder (ASD) is the term used to encompass a group of syndromes of varying severity, typified by impaired social interactions, communicative delays, and restricted, repetitive behaviours and interests (1). AS is a pervasive developmental disorder, falling under the umbrella of ASD, primarily characterized by impairments in social interaction (2). AS is distinguished from classical autism by the relative preservation of language and cognitive abilities. ASDs are generally more common in men than in women $(4.3: 1)$, with the prevalence rising to 37 per 10,000 individuals in recent years (3). The prevalence rate for AS has been estimated at 2.6 per 10,000 individuals (4).

There have been several reports, mainly anecdotal, of a link between ASD and chronic gastrointestinal (GI) symptoms; however, scientific data are scarce and often criticized. Frequent complaints have included chronic diarrhea, bloating, abdominal pain, distension and abnormal stool consistency. In a recent cross-sectional study, comparing autistic children with matched neurotypical controls as well as children with other developmental disabilities (ODD), 70\% of children with ASD reported a history of GI complaints, compared with $28 \%$ of neurotypical controls $(\mathrm{P}<0.001)$ and $42 \%$ with ODD $(\mathrm{P}=0.03)$ (5). GI problems have more commonly been linked to a 
'regressive' form of autism, characterized by loss of previously acquired skills and late onset of behavioural anomalies, not observed in the first year of life.

One of the earliest studies investigating GI anomalies in autistic children was reported by Wakefield et al (6) in 1998. In this study, 12 children with regressive developmental disorders (nine of whom were autistic) were all reported to have abnormal colonoscopies. The most consistent finding was lymphoid nodular hyperplasia (LNH), present in nine of the 12 children. Eight had mucosal abnormalities including granularity, loss of vascular pattern, patchy erythema, aphthoid ulcerations and 'red halo' signs in the cecal base. Histologically, the lamina propria was infiltrated by mononuclear cells in a focal or diffuse pattern, in the absence of intraepithelial lymphocytes, granulomata or crypt abscesses (6). This mild to moderate colitis was deemed nonspecific on the basis of not fulfilling criteria for either Crohn's disease or ulcerative colitis.

Criticism regarding the 'normalcy' of LNH in children prompted Wakefield et al (7) to perform ileocolonoscopy in 60 children with regressive developmental disorders and compare them with 37 developmentally normal controls. In this trial, ileal $\mathrm{LNH}$ was present in $93 \%$ of affected children versus $14.3 \%$ of controls $(\mathrm{P}<0.001)$, with chronic colitis in $88 \%$ of affected children versus $4.5 \%$ of controls (7).

With respect to the upper GI tract, Horvath et al (8) investigated 36 autistic children complaining of abdominal pain, bloating or chronic diarrhea by gastroscopy. The most common histological finding was reflux esophagitis (69.4\%), while $41.7 \%$ had chronic gastritis and $66.7 \%$ had chronic duodenitis in the absence of $\mathrm{H}$ pylori infection. The number of Paneth cells in autistic children was also noted to be significantly elevated compared with neurotypical controls. Autistic children also had an increased mean pancreaticobiliary fluid output following secretin stimulation compared with controls $(3.8 \mathrm{~mL} / \mathrm{min}$ versus $1.46 \mathrm{~mL} / \mathrm{min} ; \mathrm{P}<0.05)$, and this was particularly true among the subset of patients with diarrhea as a main complaint (8).

Torrente et al (9) compared the gastric biopsies of 25 autistic children with those of 10 normal controls, 10 Crohn's disease patients and 10 children with $H$ pylori infection. Eleven of the 25 autistic children had a focally enhanced gastritis, while two had mild diffuse gastritis. Immunohistochemistry results demonstrated the pattern of lymphocyte infiltration was most similar to Crohn's disease, with the exception of a striking predominance of CD8-positive over CD4-positive cells and a marked increase in intraepithelial lymphocytes. Another highly specific finding among autistic children was a dense, subepithelial basement membrane immunoglobulin $G$ deposition which was absent in the other subgroups.

ASD patients and their caregivers often report improvement on elimination diets, not only in the GI symptoms, but also in behavioural and cognitive problems such as hyperactivity, communication skills and attentiveness. Interestingly, $36 \%$ of children with ASD have a history of cow's milk and/ or soy protein intolerance in infancy (8). Also, while studies have not proven an increased incidence of celiac disease in these individuals, parents have often reported an improvement in their child's behavioural disturbances on a glutenfree diet. These benefits have not consistently been seen in randomized trials (10), however a Cochrane review (11) did report a significant reduction in autistic traits on a gluten-free casein-free diet.
One hypothesis is that ASD may be accompanied by aberrant innate immune responses to dietary proteins, leading to GI inflammation and aggravation of behavioural problems. One study (12) measuring proinflammatory cytokines in response to common dietary proteins showed a greater than two SD excess in tumour necrosis factor-alpha and interferongamma production in response to gluten and cow's milk protein among ASD children compared with controls. A subsequent study confirmed a higher prevalence of elevated tumour necrosis factor-alpha and interleukin-12 production with beta-lactoglobin and alpha-lactoglobin, but not casein, in autistic children as well as children with nonallergic food hypersensitivity, compared with normal controls (13).

Another theory suggests that abnormal intestinal permeability in children with ASD causes them to absorb fragments of incompletely broken-down peptides such as gluten or casein, which cross the blood-brain barrier and act as endogenous opioids. D'Eufemia et al (14) demonstrated a higher mean lactulose recovery in $43 \%$ of autistic subjects versus none of the controls.

The gut microflora has also been targeted as a potential player. There have been anecdotal reports of the onset of autism following broad-spectrum antibiotics, suggesting that disruption of the indigenous flora may lead to colonization by neurotoxinproducing bacteria. Autistic children have been shown to have higher counts and more species of clostridia than age- and sexmatched controls (15-17). A small prospective trial (18) demonstrated a significant but transient improvement in autistic features following a course of vancomycin therapy, with relapses presumed to occur because of persistent spores that proliferate on antibiotic discontinuation.

While genetic susceptibility is an important contributor in ASDs (19-21), the exact etiology of these pervasive developmental disorders remains unclear and is most likely multifactorial. Although the idea of a shared pathophysiology between GI disease and autism remains controversial, the evidence presented so far warrants further exploration at the very least. Be it an immune-mediated connection, versus a 'braingut axis' interplay such as seen in irritable bowel syndrome, the increased prevalence of GI symptoms in this group of patients cannot be denied, nor the added distress that these symptoms could have on an individual who is already communicatively challenged. Clearly, more studies need to be conducted to better define the relationship between ASDs and the GI tract. In the meantime, a heightened awareness and lower threshold for work-up and management of GI symptoms may help improve the quality of life of these patients who may be suffering in silence.

\section{REFERENCES}

1. Barbaresi WJ, Katusic SK, Voigt RG. Autism: A review of the state of the science for pediatric primary health care clinicians. Arch Pediatr Adolesc Med;160:1167-75.

2. McPartland J, Klin A. Asperger's syndrome. Adolesc Med 2006;17:771-88

3. Fombonne E. Epidemiology of autistic disorder and other pervasive developmental disorders. J Clin Psychiatry 2005;66(Suppl 10):3-8.

4. Fombonne E. Tidmarsh L. Epidemiologic data on Asperger disorder. Child Adolesc Psychiatr Clin N Am 2003;12:15-21.

5. Valicenti-McDermott M, McVicar K, Rapin I, et al. Frequency of gastrointestinal symptoms in children with autistic spectrum disorders and association with family history of autoimmune disease. J Dev Behav Pediatr 2006;27:S128-36. 
6. Wakefield AJ, Murch SH, Anthony A, et al. Ileal-lymphoid nodular hyperplasia, non-specific colitis, and pervasive developmental disorder in children. Lancet 1998;351:637-641.

7. Wakefield AJ, Anthony A, Murch SH, et al. Enterocolitis in children with developmental disorders. Am J Gastroenterol 2000;95:2285-95.

8. Horvath K, Papadimitriou JC, Rabsztyn A, Drachenberg C, Tildon JT. Gastrointestinal abnormalities in children with autistic disorder. J Pediatr 1999;135:559-63.

9. Torrente F, Anthony A, Path MRC, et al. Focal-enhanced gastritis in regressive autism with features distinct from Crohn's and Helicobacter pylori gastritis. Am J Gastroenterol 2004;99:598-605.

10. Elder JH, Shankar M, Shuster J, et al. The gluten-free, casein-free diet in autism: Results of a preliminary double blind clinical trial. J Autism Dev Disord 2006;36:413-20.

11. Millward C, Ferriter M, Calver S, Connell-Jones C. Cochrane Database Syst Rev 2004:CD003498.

12. Jyonouchi H, Sun S, Itokazu N. Innate response associated with inflammatory responses and cytokine production against common dietary proteins in patients with autism spectrum disorder. Neuropsychobiology 2002;46:76-84.

13. Jyonouchi H, Geng L, Ruby A, Reddy C, Zimmerman-Bier B. Evaluation of an association between gastrointestinal symptoms and cytokine production against common dietary proteins in children with autism spectrum disorders. J Pediatr 2005;146:605-10.

14. D’Eufemia P, Celli M, Finocchiaro R, et al. Abnormal intestinal permeability in children with autism. Acta Pediatr 1996;85:1076-9.

15. Finegold SM, Molitoris D, Song Y, et al. Gastrointestinal microflora studies in late-onset autism. Clin Infect Dis 2002;35:S6-16.

16. Song Y, Liu C, Finegold S. Real-time PCR quantitation of clostridia in feces of autistic children. Appl Environ Microbiol 2004;70:6459-65.

17. Parracho HMRT, Bingham MO, Gibson GR, McCartney AL. Differences between the gut microflora of children with autistic spectrum disorders and that of healthy children. J Med Microbiol 2005;54:987-91.

18. Sandler RH, Finegold SM, Bolte ER, et al. Short-term benefit from oral vancomycin treatment of regressive-onset autism. J Child Neurol 2000;15:429-35.

19. Weiss LA, Shen Y, Korn JM, et al. Association between microdeletion and microduplication at 16p11.2 and autism. N Engl J Med 2008;358:667-75.

20. Freitag CM. The genetics of autistic disorders and its clinical relevance: a review of the literature. Mol Psychiatry 2007;12:2-22.

21. Muhle R, Trentacoste SV, Rapin I. The genetics of autism. Pediatrics 2004;113:e472-86. 


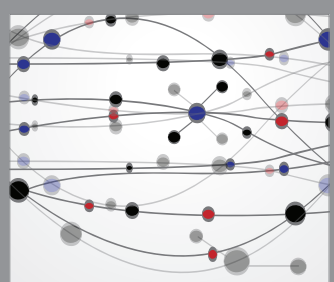

The Scientific World Journal
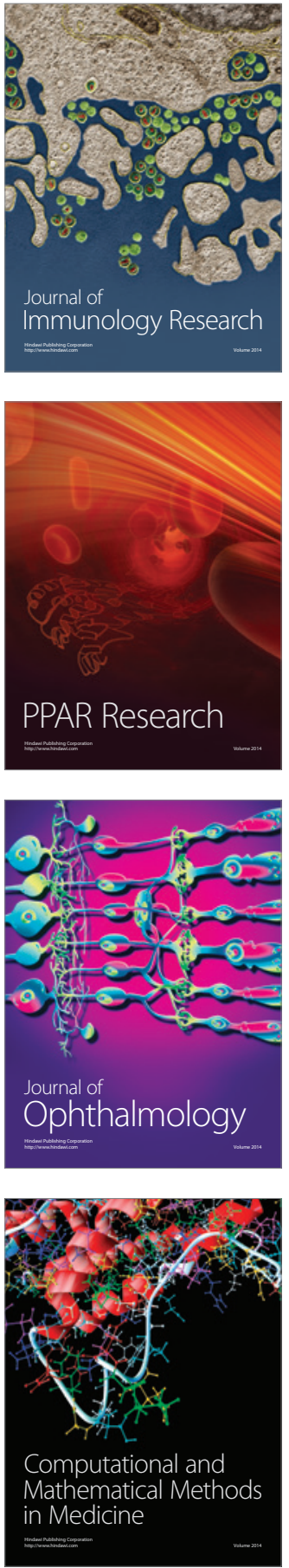

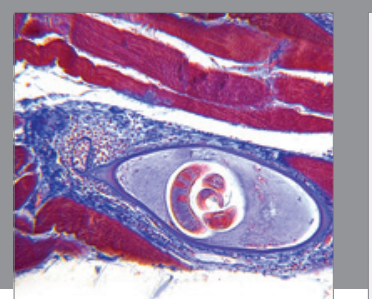

Gastroenterology Research and Practice

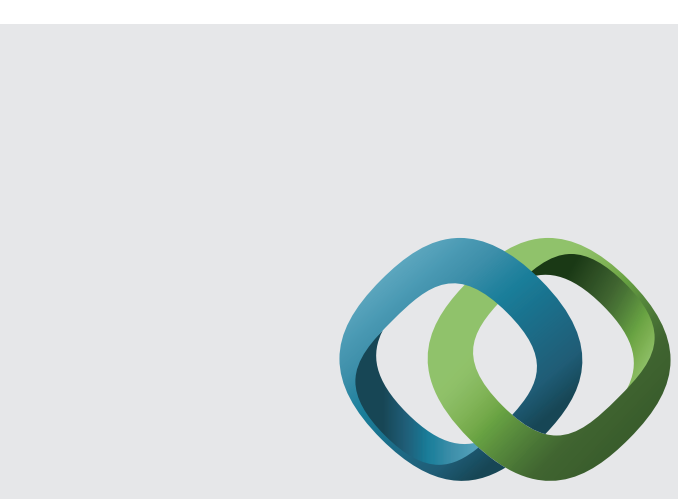

\section{Hindawi}

Submit your manuscripts at

http://www.hindawi.com
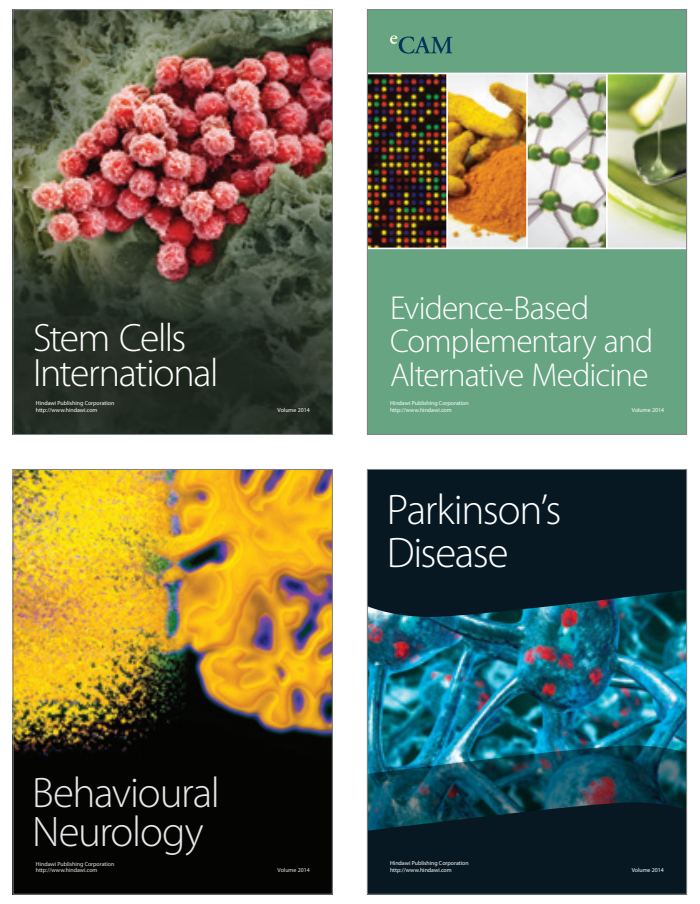
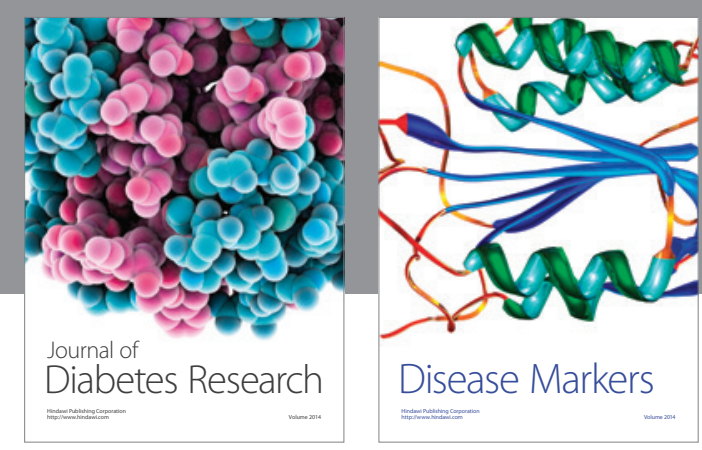

Disease Markers
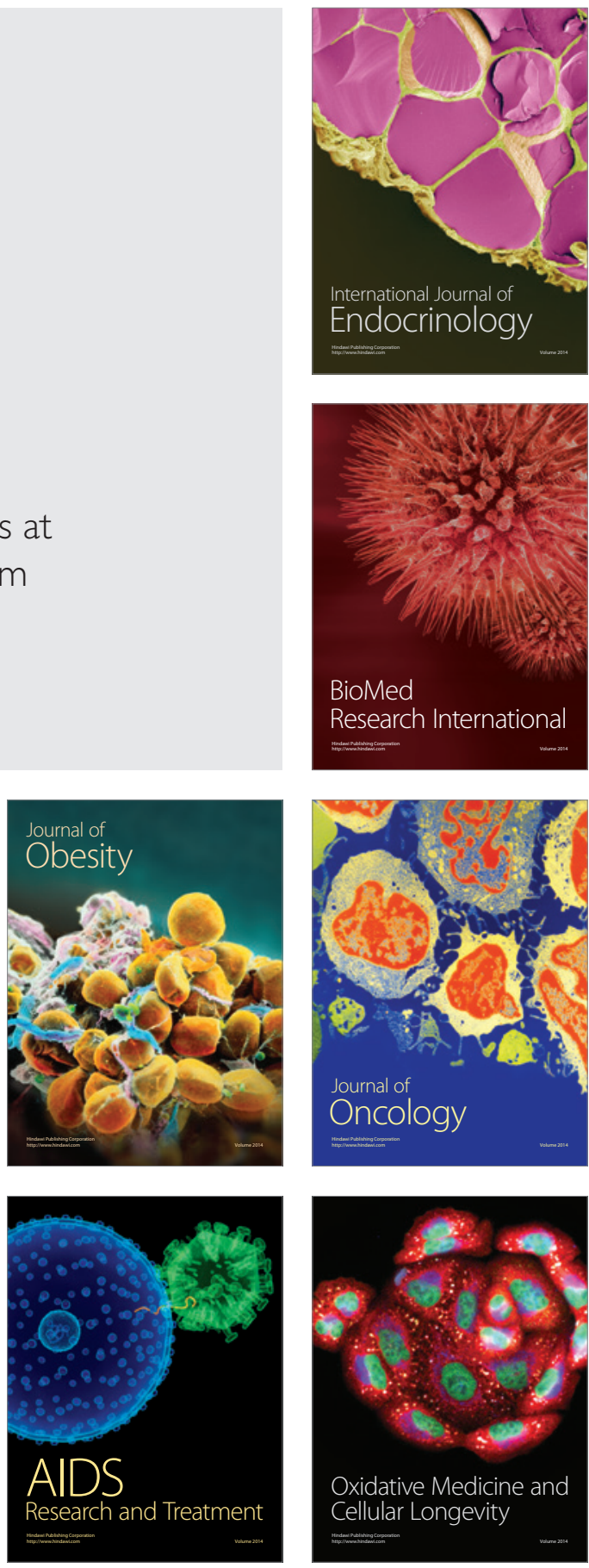